\title{
Occupational health aspects for height work in temporary and mobile sites
}

\author{
Cristina Gogelescu ${ }^{1}$, Gheorghe Solomon ${ }^{1}$, Eugenia Tudose ${ }^{1}$, Costinel Bulboacă ${ }^{1}$, \\ Adrian Ispasoiu ${ }^{2}$ \\ ${ }^{1}$ University Politehnica of Bucharest, Romania \\ ${ }^{1}$ University Transilvania of Brasov, Romania \\ E-mail:cristinameita@gmail.com,ghe.solomon@gmail.com,jenibulboaca@gmail.com, \\ costinelbulboaca@gmail.com, Adrian.ispasoiu@unibv.ro
}

\begin{abstract}
This work provides an analysis of the role and activity of occupational health monitoring by occupational medicine services for companies operating in temporary and mobile construction sites. The analysis is structured on the evidence and public statistics existing at this time, the statistical data collected from occupational medicine services that provide occupational medicine activities for a number of 10 companies with activities in mobile and temporary construction sites. Definitions, tables, statistics, and images on the general morbidity by types of diseases found in a period of 5 years are presented, from which the records for three years chosen at random by the authors were extracted. The authors' conclusions show the importance of the role of occupational medicine physician, diagnosis, and prompt treatment of intercurrent diseases, application of proactive measures, monitoring of workers with chronic diseases, smoking limitation and verification of individual and collective hygiene measures, identification, and personalization of risks. professional, performing medical examinations of occupational medicine according to the current legislation.
\end{abstract}

Keywords: occupational medicine, morbidity, diseases, checklist, medical measures

\section{Introduction}

A company that carries out activities in the field of construction has staff with different professions and training who are exposed to a wide range of risk factors, toxins, external actions that can affect their health.

The collaboration of the occupational medicine doctor with the employer in order to ensure in good conditions the medical supervision of the staff has a very important role.

The paper summarizes the role and monitoring of the Occupational Medicine Service on surveillance of workers' health so as to operate under normal conditions for a period of three years randomly selected from the last 5 years (2017-2021) by the authors, year I, II and III, for a number of 10 companies with specific activities in temporary and mobile construction sites with which there are service contracts and from where statistical data necessary for the analysis could be collected.

The control of occupational medicine is carried out in accordance with: 
Law-319/2006, Occupational Safety and Health: Chapter V Health surveillance (2) Supervision of workers' health is ensured by occupational medicine doctors [1] and H.G. (Government Decision) no. 355/2007, subsequently amended and H.G. no. 1169/ December 2011 art. 8 (1) The prophylactic medical services that ensure the supervision of workers' health are: medical examination at employment, adaptation, periodically, resumption of work, special supervision, and promotion of health at work. "Parameters, investigation procedure and scheduling medical examination at employment, periodically, the resumption of activity is established by the occupational physician, who formulates the conclusion of the examinations performed. The main objective is to monitor the health of workers at work, considering that their activity is carried out in special conditions. "Aptitude at work" means the ability of the worker from a medical point of view to carry out the activity at work in the profession / position for which the medical examination is requested (Chapter III, art. 9 (1)). [2]

The role of the occupational medicine doctor in supervising the health of workers at work

The WHO defined occupational health as: "The main goal of occupational health is to promote and maintain the highest degree of physical, mental and social well-being of all employees, regardless of occupation."

Occupational health objectives:

- placing and maintaining the worker in an environment adapted to each person's physical and mental abilities, adapting work to man and adapting man to his job, protecting workers from risk factors at work;

- its main role is to inform the employer on how to obtain and maintain working conditions that do not affect the health of employees.

- compliance with the legislation in force, the employer having the obligation to provide preventive medical services to his employees.

According to Law-418/2004, the occupational medicine doctor has the following attributions:

- establishes an annual work program for the improvement of the working environment in terms of occupational health for each employer;

- identifies risk factors and participates in their assessment actions;

- supervises the health of the employees on the basis of the legal provisions and the professional risks for the health of the employees;

- organizes the surveillance of the employees' health condition, in accordance with the particularities of the exposure to the risk factors;

- organizes first aid and emergency treatment and instructs employees on the application of their accessible first aid methods and emergency procedures, if competent;

- makes recommendations on the organization of work, the ergonomic arrangement of the workplace, the safe use of substances used in the work process, as well as the distribution of work tasks, considering the capacity and skills of employees to perform them;

- may propose to the employer the change of the job or the type of work of some employees, determined by their state of health;

- participates in the establishment of occupational health programs within the CSSM (Committee on Health and Safety at Work);

- assesses the aptitude for work in relation to the state of health and promotes the adaptation of work to the possibilities of the employees;

- prepares reports to the employer, employees, and competent authorities, in accordance with the law; 
- can contribute through its activity to scientific knowledge in the field of occupational health, respecting the ethical principles applied in medical research;

- ensures the management of the occupational medicine medical services. [3]

\section{The current stage}

For the occupational medicine doctor who provides specialized services for a construction company, there are a series of question marks on the answer of which the medical conduct depends:

- Has the medical service been formally hired or is there a real collaboration with the exact observance of the spirit and letter of the law?

- Does the employer know his rights and especially the obligations related to safety and health at work?

- How big is the construction company, in terms of number of employees and what area does it cover in the territory?

- What is the object of activity: civil constructions, roads, and bridge constructions, hydrotechnical constructions, industrial, metallic constructions, interior arrangements, energetic constructions?

- What tools and machines do they work with, are they high-performance, or are they "patched" and old?

- Do you work with seasonal workers, minors, "without documents"?

- Do you work shifts? What is the duration of an exchange?

- Are there rest areas, rest, dining, bathroom, possibly adequate living space arranged and maintained?

- Are there any personal protective equipment that is used correctly and, especially when worn by workers?

- Are they affected by chronic diseases?

- Are they affected by alcohol, tobacco, drugs (drugs or not)?

- Do you work indoors or outdoors?

- Do you work on the ground and / or at height?

- Do machines and cars also run-on public roads? Are all traffic safety requirements met?

- Is there a controlled water source?

Knowing the answer to these few questions from what can be asked, along with visiting workplaces, the study of safety data sheets for substances used, allows the doctor to correctly interpret clinical health data in the context of occupational exposure. [4]

The role of medical analysis in discovering / establishing work aptitude

Construction work is one of the professional activities that makes victims through work accidents, which can cause various occupational or profession-related illnesses.

The occupational medicine services provided include:

- completing and recording individual medical files;

- issuing the aptitude card and advising the employer;

- spontaneous consultations of occupational medicine;

- collaboration with the human resources and occupational safety services;

- organizing and participating in the professional risk assessment;

- monitoring the health of employees;

- professional reorientation in case of occupational disease or other chronic diseases; 
- counseling on adapting work to the psychophysiological characteristics of employees;

- counseling for substantiating the health and safety strategy at work;

It is important that these services be performed through an occupational medicine clinic that can develop in addition to diagnosing and supervising / recovering medical conditions.

For construction companies, mentions will be made in the contract so that all workers benefit from medical tests for "working at height", regardless of their job / function.

It is also important for workers to be honest when they have a medical condition and to tell the occupational physician so that he can analyze and recommend the necessary measures, dispense with their condition through the family doctor or even stop the activity or change of job if the condition is generated by activity and / or work.

To exemplify the role of occupational medicine and medical services among workers questions were summarized in a checklist that was completed by workers from 10 different sites. [7]

\section{Checklist of working conditions in construction sites on medical control}

This list aims at evaluating the activity regarding the occupational medicine services in order to improve it.

For this we ask you objectivity and sincerity in completing the questionnaire, it is not necessary to mention your name and sign.

\begin{tabular}{|c|c|c|c|c|}
\hline No. & Question & Yes & No & $\begin{array}{l}\text { I do not } \\
\text { know }\end{array}$ \\
\hline 1. & \multicolumn{4}{|l|}{ Consider that you are well informed about: } \\
\hline 1.1. & The risks you are exposed to & & & \\
\hline 1.2. & The effects that risk factors can have in the short / long term & & & \\
\hline 1.3. & Possibilities to reduce the level of risks & & & \\
\hline 1.4. & Occupational medicine medical checks & & & \\
\hline 2. & \multicolumn{4}{|l|}{ You consider the arrangement of the workplace: } \\
\hline 2.1. & Very good & & & \\
\hline 2.2. & Good & & & \\
\hline 2.3. & Satisfying & & & \\
\hline 2.4. & Unsatisfactory in terms of security, aesthetically & & & \\
\hline 3. & \multicolumn{4}{|c|}{$\begin{array}{l}\text { The arrangement of non-workplaces (locker rooms, toilets, dining places, etc.) is } \\
\text { considered: }\end{array}$} \\
\hline 3.1. & Very good & & & \\
\hline 3.2. & Good & & & \\
\hline 3.3. & Satisfying & & & \\
\hline 3.4. & Unsatisfactory functionally, aesthetically & & & \\
\hline 4. & \multicolumn{4}{|l|}{ What medical examinations have you performed: } \\
\hline 4.1. & Medical inspection at employment & & & \\
\hline 4.2. & Periodic medical check-ups & & & \\
\hline 4.3. & Resumption exams, special supervision & & & \\
\hline 5. & \multicolumn{4}{|c|}{$\begin{array}{l}\text { What investigations are necessary to establish the ability of employees to perform } \\
\text { functions specific to each job you have performed: }\end{array}$} \\
\hline 5.1. & general clinical examinations & & & \\
\hline
\end{tabular}




\begin{tabular}{|c|c|c|}
\hline 5.2. & assessments of visual acuity and chromatic sense & \\
\hline 5.3. & auditory acuity assessments (audiograms) & \\
\hline 5.4. & psychological testing & \\
\hline 5.5. & electrocardiograms & \\
\hline 5.6. & blood sugar & \\
\hline 5.7. & ventilatory functional tests (spirometry) & \\
\hline 6. & \multicolumn{2}{|l|}{ Do you know the conclusions of the skills sheet that was issued to you? } \\
\hline 6.1 . & with the opinion "able" & \\
\hline 6.2. & with the opinion "able with condition" & \\
\hline 6.3 . & with the opinion "temporarily unable", "unable" & \\
\hline 7. & \multicolumn{2}{|c|}{ Do you know the difference between occupational diseases and occupational diseases? } \\
\hline 7.1. & & \\
\hline 8. & \multicolumn{2}{|c|}{$\begin{array}{l}\text { After the medical check-up, did you find out that you suffer from any disease (diabetes, } \\
\text { high blood pressure, etc.)? }\end{array}$} \\
\hline 8.1 & & \\
\hline 9. & \multicolumn{2}{|c|}{ Do you know what is expected of you at work on the line of Labor Security? } \\
\hline 9.1 & & \\
\hline 10. & \multicolumn{2}{|c|}{$\begin{array}{l}\text { Are there workers at work who care about you as a person? (if you work safely, if you } \\
\text { have a proper PPE, if you are sick, if you have been drinking or in other dangerous } \\
\text { situations) detail: }\end{array}$} \\
\hline 10.1 & …............. & \\
\hline 11. & \multicolumn{2}{|c|}{$\begin{array}{l}\text { Regarding the COVID pandemic } 19 \text { list what measures have been taken at your } \\
\text { workplace }\end{array}$} \\
\hline 11.1 & \multicolumn{2}{|l|}{ ……......................... } \\
\hline 12. & \multicolumn{2}{|l|}{ What measures do you propose to improve working conditions? } \\
\hline 12.1 . & \multicolumn{2}{|l|}{ 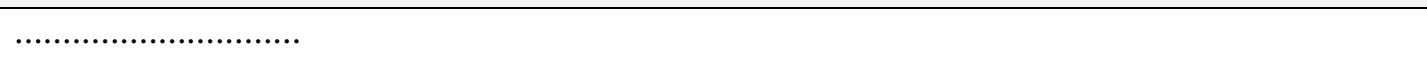 } \\
\hline & \multicolumn{2}{|l|}{ 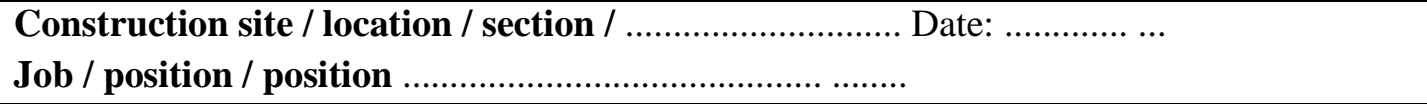 } \\
\hline
\end{tabular}

From the analysis of these questionnaires, it results that the workers benefit from occupational medicine services, know the risks to which they are exposed as well as the prevention measures imposed / recommended by the employer. Some of these workers discovered medical conditions they did not know about - hypertension, diabetes.

Organizing medical control at a construction company

According to the protocol of medical control at employment, resumption of activity and periodic medical control annually, to assess the health and fitness to work, all employees were examined annually according to the established schedule.

The on-the-job medical check-up was performed at an occupational medicine clinic and the regular medical check-up was generally performed on construction sites, in specially arranged spaces.

A minimum number of investigations were performed to establish the ability of employees to perform job-specific functions.

It can be mentioned that during the analyzed period the same investigations were carried out on the workers. 
The medical check-up was generally organized on site, in a specially arranged barracks.

Depending on the number of medical examinations performed in the analyzed years, the type of examinations performed in table no. 1 is presented.

Table no.1 - Evidence of medical checks by category in the analyzed period

\begin{tabular}{|l|l|l|l|l|l|l|l|l|l|}
\hline Year & $\begin{array}{l}\text { periodic } \\
\text { medical } \\
\text { check- } \\
\text { ups }\end{array}$ & $\begin{array}{l}\text { medical } \\
\text { examinat } \\
\text { ions at } \\
\text { employm } \\
\text { ent }\end{array}$ & $\begin{array}{l}\text { adap } \\
\text { tation } \\
\text { exams }\end{array}$ & $\begin{array}{l}\text { resump } \\
\text { tion } \\
\text { exams }\end{array}$ & $\begin{array}{l}\text { special } \\
\text { supervisi } \\
\text { on } \\
\text { examina } \\
\text { tions }\end{array}$ & $\begin{array}{l}\text { clinical } \\
\text { balance } \\
\text { examinations } \\
\text { upon cessation } \\
\text { of activity }\end{array}$ & $\begin{array}{l}\text { mo } \\
\text { re }\end{array}$ & $\begin{array}{l}\text { spontan } \\
\text { eous } \\
\text { consult } \\
\text { ations }\end{array}$ & $\begin{array}{l}\text { no. } \\
\text { work } \\
\text { ers }\end{array}$ \\
\hline I & 322 & 368 & 0 & 1 & 1 & 1 & 2 & 0 & 694 \\
\hline II & 454 & 317 & 0 & 8 & 0 & 0 & 1 & 0 & 780 \\
\hline III & 387 & 266 & 0 & 2 & 2 & 0 & 8 & 0 & 665 \\
\hline
\end{tabular}

Analysis of the health of workers in a construction company for 3 years

Medical investigations for a "builder" are complex.

Most workers work at height, exposed during the working day to noise, vibration, weather, solar radiation, dust (cement, sand, lime, gypsum, plaster, asbestos - from asbestos-cement boards, wood, etc. in some situations), chrome, risk of accidents (falling from a height, crushing, slipping, burning, electric shock, etc.).

The physical effort is high or very high, and the work requires manual maneuvers for lifting - carrying - transporting weights, forced positions in a non-physiological position.

The basis of these investigations is the occupational risk exposure form, completed correctly and in full by the employer, part of the medical file.

After a comprehensive analysis of the results of medical examinations, aptitude sheets were issued (in two copies - for employer and worker), including general medical recommendations, of which apt / conditioned apt / temporarily unfit / unfit presented below in table no. 2

Table no.2 - Evidence of occupational medicine medical approvals for the years 2017-2019

\begin{tabular}{|l|l|l|l|l|l|l|}
\hline \multirow{2}{*}{ Year } & \multirow{2}{*}{$\begin{array}{l}\text { Category } \\
\text { professional }\end{array}$} & \multirow{2}{*}{ No employees } & Occupational medicine medical conclusion \\
\cline { 4 - 7 } & & & able & $\begin{array}{l}\text { able } \\
\text { conditioned }\end{array}$ & $\begin{array}{l}\text { temporarily } \\
\text { unable }\end{array}$ & unable \\
\hline I & \multirow{2}{*}{$\begin{array}{l}\text { Office staff, worker - } \\
\text { wI }\end{array}$} & 694 & 650 & 44 & 0 & 0 \\
\cline { 3 - 7 } & 780 & 758 & 22 & 0 & 0 \\
\cline { 3 - 7 } & 665 & 651 & 14 & 0 & 0 \\
\hline
\end{tabular}

The issuance of fitness sheets with the specification "conditioned fit" were largely established based on cardiovascular disease and diseases of nutrition and metabolism, which contraindicates intense physical exertion, neuro-mental overload.

It can be seen from the records that the opinions with "fit conditioning" conclusions decrease significantly every year.

During the period analyzed at the time of the medical examination, no occupational diseases were diagnosed.

In figures no. 3, 4, 5 highlight the general morbidity structures for the analyzed years 


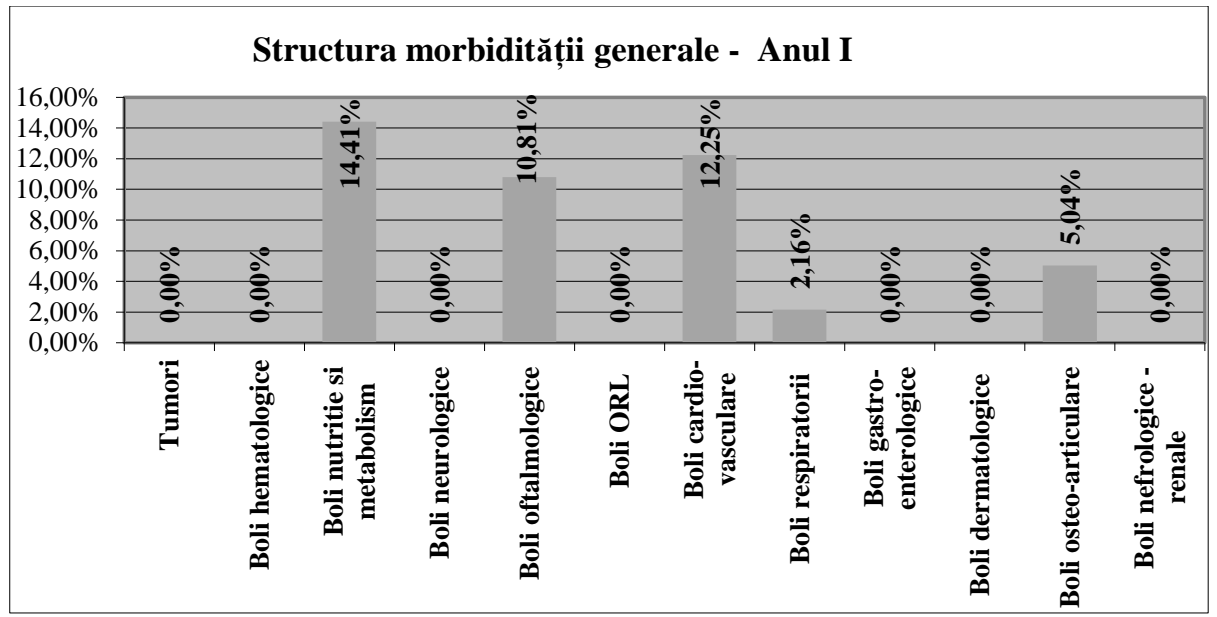

Figure no.1 The structure of general morbidity for the first year

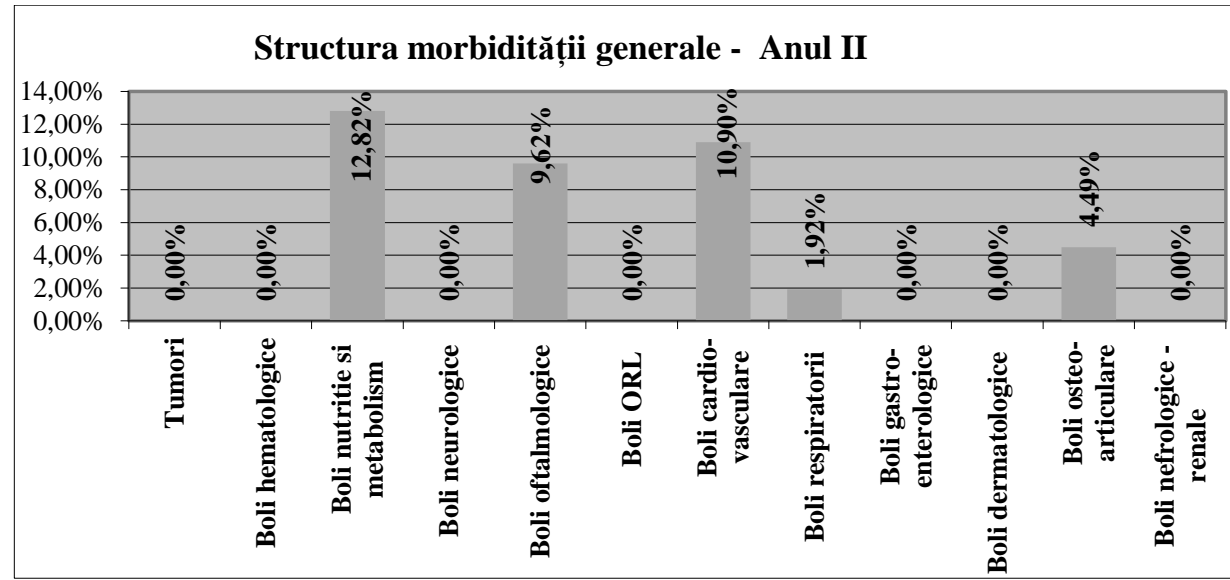

Figure no.2 The structure of the general morbidity for the second year

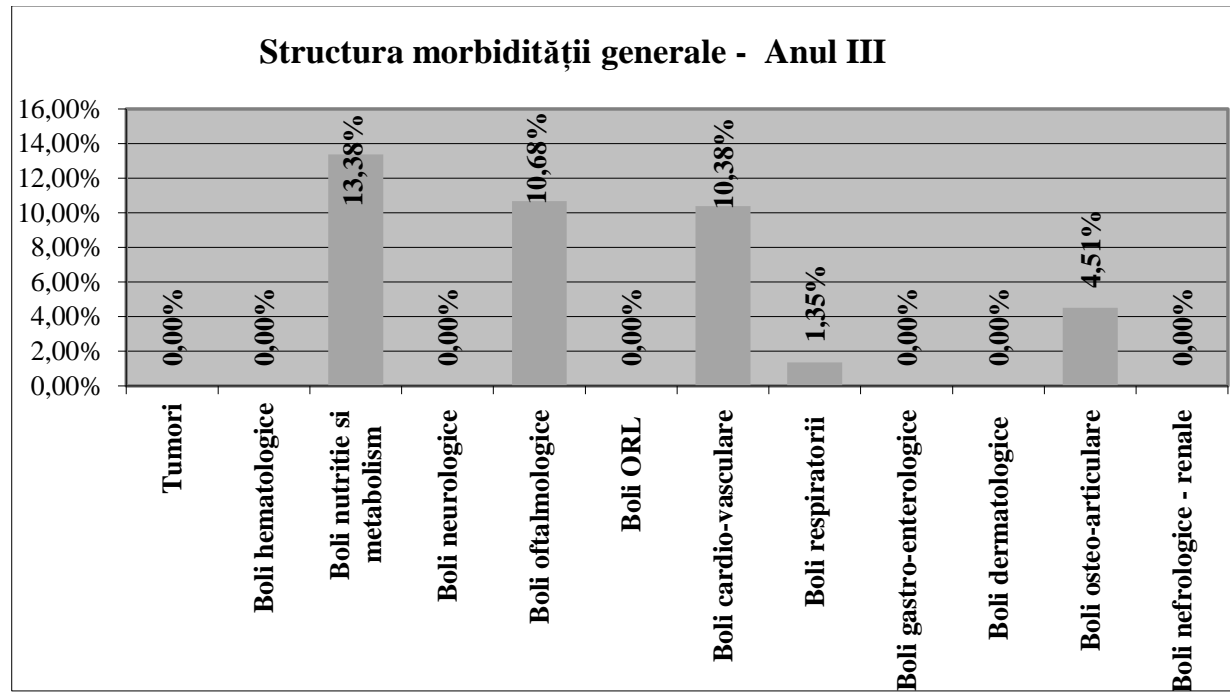

Figure no.3 General morbidity structure for year III 
When analyzing the general morbidity, there is a peak of morbidity in nutrition and metabolism diseases, followed by cardiovascular diseases and ophthalmic diseases as presented in table no. 3

Table no. 3 The structure of general morbidity in the analyzed period

\begin{tabular}{|l|l|l|l|}
\hline \multirow{2}{*}{ Affection category } & Year & II & III \\
\cline { 2 - 4 } & I & $12,82 \%$ & $13,38 \%$ \\
\hline $\begin{array}{l}\text { Nutrition and metabolism } \\
\text { diseases }\end{array}$ & $14,41 \%$ & $10,90 \%$ & $10,38 \%$ \\
\hline Cardiovascular diseases & $12,25 \%$ & $9,62 \%$ & $10,68 \%$ \\
\hline Ophthalmic diseases & $10,81 \%$ & $1,92 \%$ & $1,35 \%$ \\
\hline Respiratory diseases & $2,61 \%$ & $4,49 \%$ & $4,51 \%$ \\
\hline Osteo-articular diseases & $5,04 \%$ & & \\
\hline
\end{tabular}

It is also found that the percentage of these diseases is decreasing.

From the analysis of the data presented above it can be concluded:

Nutrition and metabolism diseases, cardiovascular diseases have an increased frequency and are due to risk factors such as sedentary lifestyle and mental stress, which can be combated through a healthy lifestyle and ensuring mental comfort.

These types of conditions require proper treatment and close monitoring to minimize the risk of accidents at work.

Particular attention should be paid to all cases of illness found. [6]

Ophthalmic diseases require a correct and active monitoring for the staff working with powders without goggles, the correction of both refractive errors (myopia, farsightedness, presbyopia) as well as specialized treatment of any ophthalmological pathology regardless of the greater or lesser severity of that condition. [6]

\section{Determining risk factors for construction workers on construction sites}

Staff working at height must be in very good health and balance.

Epilepsy, chronic diseases of the nervous system (including alcoholism), mental illness, balance disorders of any kind, deafness, untreated hypertension, some heart diseases, some lung diseases, some chronic ophthalmic diseases, and acute eye conditions until healing are contraindications for working at height, even for a day.

People working at height are carefully selected by the employer, based on a thorough and rigorous medical check-up, medical references and after performing a psychological examination.

Any change in the state of health (whether physical or mental) of people working at height will need to be reported to the direct / team leader and / or other responsible persons, and the worker should be referred to a doctor for prompt remediation. health problems. Until the problem of the worker's health is solved, he will be stopped from working at height.

Particular importance must be given to the technical equipment provided for working at height. To this end, adequate safety and ergonomic conditions shall be ensured on a convenient surface, as well as adequate equipment to ensure and maintain safe working conditions. Priority must also be given to collective protection measures over individual protection measures. The type, dimensions of the technical / protective equipment (stairs, scaffolding, passage elements, floors, work / safety ropes, safety belts), as well as the access routes must be adapted to the nature of the work to be performed, the tasks 
for which they are used, foreseeable difficulties, to allow evacuation in case of imminent danger, and not to generate additional risks of fall / injury.

The presence in a unit of a large number of medical certificates for such diseases is an additional argument, along with the ergonomic analysis of the activity, for the need for changes in the technological process or in the organization of work.

Smoking is a recognized risk factor for respiratory cancer and cardiovascular disease.

Collaboration between the occupational physician and the recovery physician [5]

A good collaboration between the occupational medicine doctor and the medical recovery doctor so that it is reflected in the health condition of the workers depends on the factors highlighted in table no. 4 below:

Table no. 4 - Evidence of individual / particular factors

\begin{tabular}{|l|l|}
\hline Intrinsic-individual factors & \multicolumn{1}{|c|}{ Extrinsic-particular factors } \\
\hline - The weight & - Physical stress \\
- Hypotonia & - Stress \\
- Hyperlaxity & - Humidity and drafts \\
- Hydro electrolytic disorders & - Psycho-behavioral factors \\
- Endocrine-metabolic pathology & \\
- Cardiovascular adaptation & \\
- Age, sex, constitutional type, lifestyle & \\
\hline
\end{tabular}

Most of the workers who were diagnosed with medical conditions followed the medical dispensary of occupational medicine. Thus, the aptitude "conditioned" was reduced.

\section{Conclusions}

In order to increase the level of health at work in the field of construction, it is important to understand the links between the risk factors associated with health and accidents at work.

In the conditions of continuous development of technologies, the organization at work based on process improvements, good practices and modernization of methods and equipment is of particular importance along with the premature diagnosis of diseases based on current telemedicine.

\section{Recommendations for medical measures:}

- Diagnosis and prompt treatment of intercurrent diseases of various etiologies, in order to identify, establish the level of impairment and prevent the aggravation of the situation, as well as to reduce the increase in the number of days of temporary incapacity for work by proactive methods;

- Monitoring workers with chronic diseases with technical equipment, periodic returns to control, awareness of the need to follow the prescribed treatments, as well as timely observation of any changes that may affect both health and work capacity;

- Limiting smoking and checking compliance with individual and collective hygiene measures;

- Identifying and personalizing the risks that are generated by occupational exposure;

- Carrying out the medical examination at employment, resuming the activity, periodic medical control according to the current legislation.

Compliance with these recommendations maintains the ability to work at the appropriate parameters and obviously contributes to improving the health of employees. 


\section{References}

[1] *** - Law on Safety and Health at Work no. 319/2006;

[2] *** - H.G. no. 355/2007, subsequently amended by H.G. no. 1169 / December 2011 - regarding the surveillance of the workers' health;

[3] *** - Law no. 418/2004 - the specific professional status of occupational medicine doctors

[4] Elena-Ana Păuncu, Florina Gherman - Professional risk-aspects of work medicine in construction, Ed. ... 2019 p. ...

[5] Adriana Sarah Nica, Florina Ojoga, Andreia Murgu, Department of Medical Recovery, University of Medicine "Carol Davila - Premises for recovery of occupational medicine, recovery medicine Ed. ... 2019 p. ...

[6] Reports Occupational Medicine Clinic- analysis 3 years from 2017-2021 different companies

[7] Checklist of working conditions in construction sites related to medical control 